\title{
Camptodactyly in a painting by Dirk Bouts (c. 1410-1475)
}

\author{
W Hijmans MD ${ }^{1} \quad J$ Dequeker MD PhD²
}

J R Soc Med 2004;97:549-551

In 1464 Dirk (Dieric) Bouts received the commission for The Last Supper from the brotherhood of the Holy Sacrament of the Church of St Peter in Leuven. This 'masterpiece' ${ }^{1}$ is a triptych with a painting of the Jewish Passover on the left lower wing. A detail is presented in Figure 1: a woman with a white turban holds the biblical 'bitter herb' (Exodus 12:8) in her right hand. One also notices a hyperextension of the metacarpophalangeal (MCP) and the distal interphalangeal (DIP) joints of the right fifth finger with the proximal interphalangeal (PIP) slightly flexed. In the following paragraphs the various possibilities to explain this unusual presentation will be discussed. Our conclusion leads to a suggestion about the identity of the person depicted.

\section{THE DIAGNOSIS}

An artifact, a mistake, is an obvious first choice to explain the unusual presentation of the fifth finger. It is, however, an unlikely explanation because of Bouts' strong reputation for attending to detail and leaving little to chance. He is for instance known to have made extensive technical corrections and adjustments to achieve the effects he sought. ${ }^{2}$

Mannerism is a next choice. This too is unlikely, because then one would expect a flexion of the DIP joint in question. In addition, mannerism is not in the style of Dirk Bouts, nor is it seen in the works of his son Albrecht, whose relevant paintings will be discussed later. A convincing example of mannerism can be seen in the painting Madonna and Child (Figure 2) by Quinten Massijs (1465-1530).

An isolated positioning of the fifth finger with hyperextension of the DIP joint could be functional-for instance, as a result of pressure or the grasping of an object. Examples are easy to find. We choose a Mother and Child (Figure 3), because it is classified as a painting 'after Bouts'. The positioning of the fifth finger of the lady with the turban cannot, however, be the result of external pressure or grasping.

Trauma should also be mentioned and this cause is impossible to exclude.

There is little in favour of a Heberden's node, a form of polyarticular nodular osteoarthritis, localized in the DIP

${ }^{1}$ University of Leiden, The Netherlands; ${ }^{2}$ University of Leuven, Belgium Correspondence to: Dr W Hijmans, 14 Vondellaan, NL-2111 CN Aerdenhout, The Netherlands

E-mail: w.hijmans@planet.nl

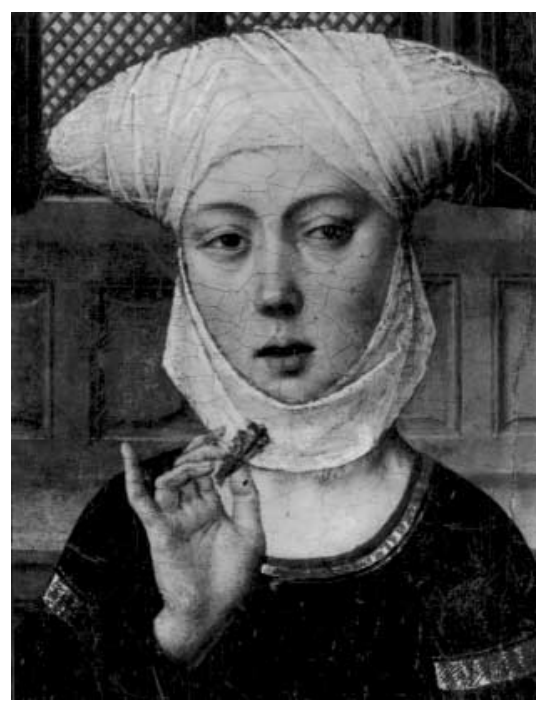

Figure 1 Detail from The Last Supper, by Dirk Bouts (from the Royal Institute for Cultural Heritage, Brussels, with permission)

joint. In our case only one finger is involved and the age of the woman argues against this presentation of osteoarthritis. For the same reasons Bouchard's nodes, localized in the PIP joints, can be excluded.

In rheumatoid arthritis one expects the involvement with flexion and dislocation of the proximal joints of more than one finger.

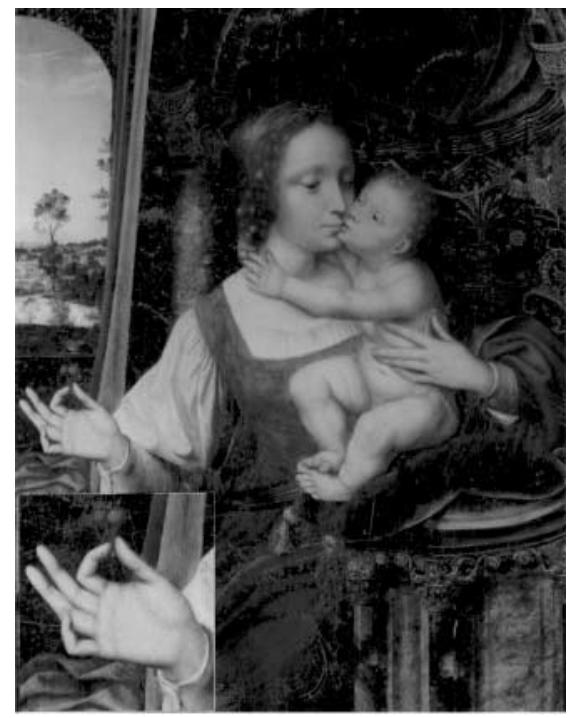

Figure 2 Madonna and Child, by Quinten Massijs (from the Mauritshuis Museum, with permission) 


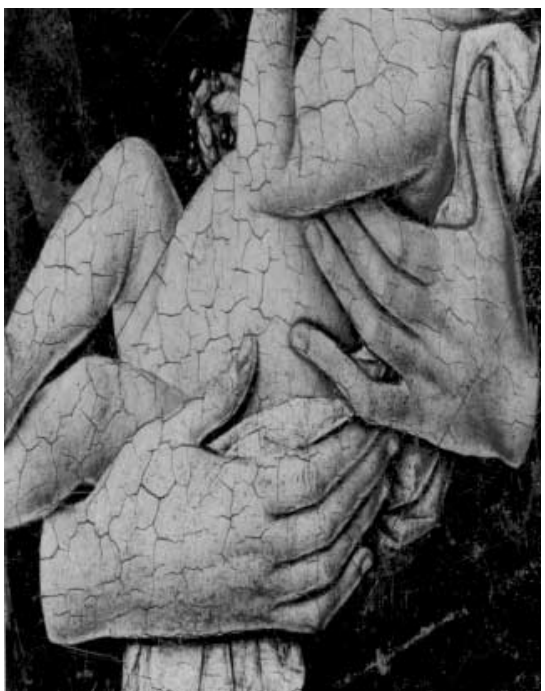

Figure 3 Detail from Mother and Child, 'after Bouts' (with permission from Museo Correr)

The hallmark of clinodactyly is the lateral displacement of the fingers and this is not seen in our case.

A claw-hand deformity can be excluded: it is defined by a hyperextension of the MCP joints in combination with flexed interphalangeal joints.

Arachnodactyly can also be excluded. It is part of Marfan's syndrome, a generalized disorder with abnormalities of the eye and an excessive length of long bones, including the fingers. ${ }^{3}$

Our diagnosis of preference is camptodactyly. In its localized form it is characterized by a congenital fixed flexion deformity of the proximal interphalangeal joint in combination with hyperextension of the metacarpophalangeal and the distal interphalangeal joints, with a preference for the fifth finger.

\section{BOUTS THE SON, AND OTHER PAINTERS}

The central question to be discussed here concerns the uniqueness of our observations. In his detailed study Bruno ${ }^{3}$ reports the presence of camptodactyly in 39 paintings and drawings by 25 Italian Renaissance artists. We reviewed 29 reproductions and one original painting of 22 of these artists and concluded that in none of these were the criteria for camptodactyly satisfied - flexion of the PIP joint in combination with a spontaneous hyperextension of the DIP and the MCP joints. In Sketchbook of the Hand, with an introduction by J-P Bailly, ${ }^{4}$ prints by 34 artists of 35 hands from male and 38 from female models could be analysed in sufficient detail to warrant the conclusion that features of camptodactyly were not present. They covered a period from the 15th to the 20th century.

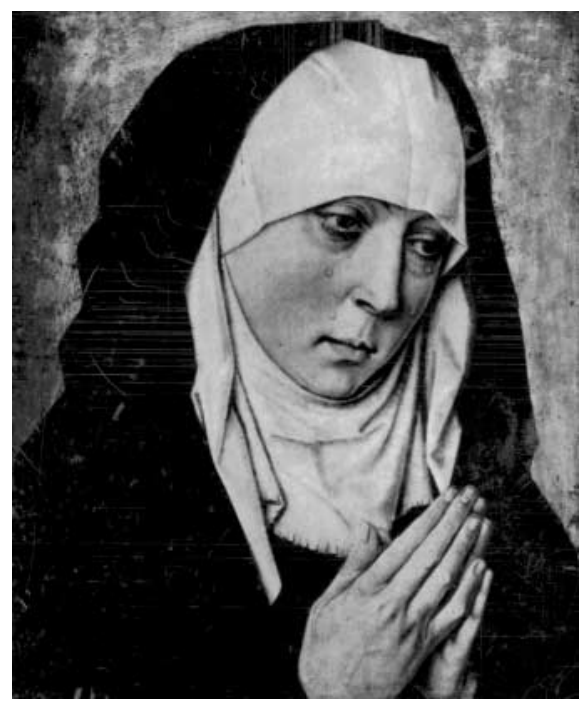

Figure 4 Mater Dolorosa, by Dirk Bouts (from the Organizing Committee of the Bouts Exhibition, Delf 1957-1958, with permission)

Our own material included 121 painters from the Southern Netherlands area who lived in the second part of the 15th and the first part of the 16th century. Hands from 546 males and 518 females were analysed. Camptodactyly was considered to be present only five times. Dirk Bouts' woman with the turban (Figure 1) has already been mentioned. The second example is his Mater Dolorosa (Figure 4). The three other paintings were by his younger son, Albrecht. In two almost identical paintings he portrayed the Mater Dolorosa (Figure 5). The third is the woman with the widow's veil in the right wing of his triptych The Ascension of Maria (Figure 6). In addition there exist exact copies of the Mater Dolorosa by Dirk Bouts, painted by followers after his death, but these pictures do

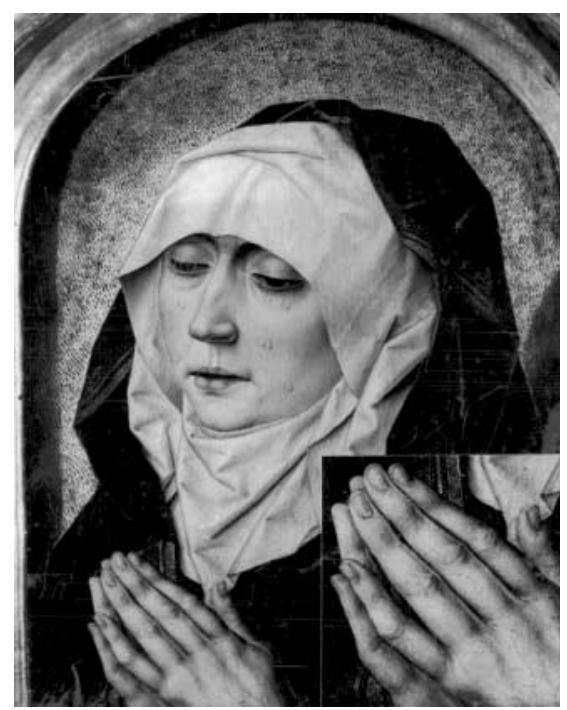

Figure 5 Mater Dolorosa, by Albrecht Bouts (from SuermondtLudwig-Museum, Aachen, with permission) 


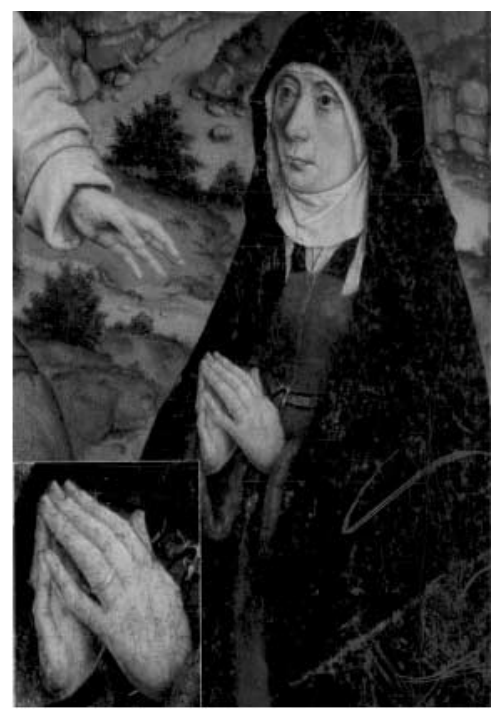

Figure 6 Detail from The Ascension of Maria, by Albrecht Bouts (from the Royal Institute for Cultural Heritage, Brussels, with permission)

not contribute to our discussion for the very reason that they are exact copies.

\section{HYPOTHESIS}

These observations on the fingers in five paintings by Bouts father and son, and their absence in works by other artists from the same era and later, lead us to hypothesize that the five women depicted are one and the same person. It is noteworthy that, in an otherwise exact copy of Dirk Bouts' Mater Dolorosa, such signs are absent. The positioning of the fingers has been 'corrected' (Figure 7) by the anonymous artist(s). The second part of our hypothesis concerns the identity of the woman concerned. According to prevailing opinion, ${ }^{5}$ the woman in the widow's dress in the right panel of Albrecht Bouts' The Ascension of Maria represents Elisabeth van Voshem, widow of Dirk Bouts and Albrecht's stepmother. This painting is dated around 1500, whereas the triptych by Dirk Bouts was delivered in 1468. If indeed Elisabeth van Voshem served as a model for these two pictures, the apparent difference in age is about that to be expected. Support for this notion can be obtained from registry data. Dirk Bouts married his first wife in or before 1448. She died in 1473. He then married Elisabeth van Voshem, a rich widow, in 1474 Dirk Bouts died in 1475 and Elisabeth in 1506.

A final point concerns the use of a live model. This should not come as a surprise, even if it is a family member. Artists are good observers and tend to paint what they see. ${ }^{6,7}$ Bouts father and son preferred not to obscure reality by flattery.

Acknowledgments We thank Dr J Ridderbos, Faculty of Arts, Groningen University, for criticism and advice, Mrs A

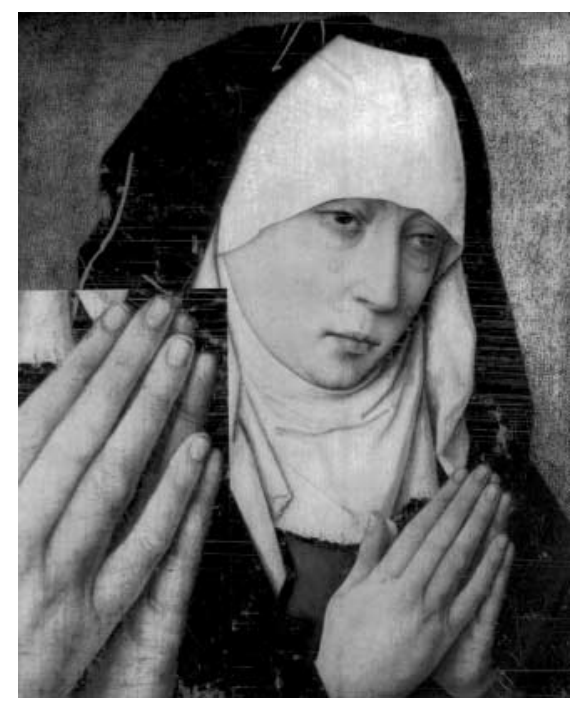

Figure 7 Copy of Dirk Bouts' Mater Dolorosa, by an anonymous artist from National Library Picture Gallery, London, with permission)

M Caulkin for editorial assistance and Mr K van den Ham for expert photography. Financial support for the initial phase of this study was received from the Dutch Rheumatism Association. Permission to reproduce the illustrations was kindly given by the Mauritshuis Museum, The Hague, The Netherlands (Figure 2), the Museo Correr, Venice, Italy (Figure 3), the National Library Picture Gallery, London, UK (Figure 7), the Royal Institute for Cultural Heritage, Brussels, Belgium (Figures 1, 6), the Suermondt-Ludwig-Museum, Aachen (Figure 5) and the Organizing Committee of the Buts exhibition, Delft, 1957-1958 (Figure 4). The Princes' Czartoryski Foundation (Cracow, Poland) kindly made available photographs of the Mater Dolorosa by Albrecht Bouts (not reproduced) which proved essential for formulation of the hypothesis.

\section{REFERENCES}

1 Smeyers M. Dirk Bouts: Catalogue of The Exhibition. Leuven: Peeters, 1998

2 Hijmans W. Extreme exorotation of a foot in a painting by Dirk Bouts (c. 1464). Ann Rheum Dis 2001;60:1152-3

3 Bruno G. Malformazioni della dita della mane nella patologia e nell'arte (Aracnodactylia, klinodactylia, kamptodactylia). Minerva Med 1959;92:3685-91

4 Bailly J-C. Introduction to La Mano, Album dei disegno. Paris: Bibliothèque de l'Image, 2000

5 Smeyers M. Dirk Bouts, Schilder van de Stilte. Leuven: Davidsfonds, 1998

6 Dequeker J. Benign familiar hypermobility syndrome and Trendelenburg sign in a painting by Peter Paul Rubens (1577-1640). Ann Rheum Dis 2001;60:894-5, 2002;61:182

7 Dequeker J, Boogaerts M. Clinical features suggestive of lymphadenopathy in a painting by Marinus van Reymerswaele. $J R$ Coll Physicians Edinb 2003;33:221-2 